\title{
Research Designs, Survey and Case Study
}

\author{
Dr. Mcchester Odoh And Dr. Ihedigbo Chinedum E. \\ Department Of Computer Science Michael Opara University Of Agriculture, Umudike, Abia State
}

\section{Introduction}

In every research effort, the first issue is to define the research problem properly, that is, the problem to be investigated or solved. The next issue is to select the research design. The research design occupies a very critical point in research since the success of the entire research work depends largely on the research design. It is the structure and planning of the entire approach to a problem for research.

Research design answers some crucial questions such as "how was the data collected or generated, and how was it analyzed"

In other words, it shows your reader how you obtained your result and why in this study survey research design and case study research designs are discussed.

\subsection{What is research?}

The subject matter of research design cannot be discussed without first having an idea of what research is all about. Research means to search again to take a cursory and curious look on a phenomenon that the research is interested in studying. Broadly speaking, research is the process of finding out the solution to a problem. Research is a clear activity with suppose that its result will contribute to, or constitute the solution of a real problem (Unyimadu, 2005:1).

In a scholarly sense, research means a systematic, objective and through investigation of a subject or problem in order to discover relevant information or principles. It ultimately represents a way of thinking; of looking at accumulated facts so that a collection of data speaks to the mind of the research is the manner in which knotty problems are solved in an effort to push back the frontiers of human ignorance. Research is a probing for truth, an extension of the reasoning abilities that are used in everyday situation; it includes analysis of information relevant to the problem being considered (Ikeagwu, 1998:3).

\subsection{Research Design: An Overview}

Research designs differ depending on the research purpose. The importance of research purpose lies in the fact that each study has its own specific purpose which differentiates it from another study (Sellitz et al, 1959:50 in Ikeagwu ms Cit: 168).

Research purposes fall into a number of broad categories. One category enables researchers to achieve new insights into some unusual occurrences or happenings, or to gain familiarity with them, in order to identify more precise research problems or to formulate hypothesis. Others serve to enable researchers to describe vividly and accurately the characteristics of particular individuals, situations or groups, and to determine the frequency with which some events occur or with which view are associated with others. They enable researcher to test hypothesis of causal relationship between variables.

Studies that attempt to gain familiarity with subject matters or to achieve new insights make discovery of ideas and insights their major emphasis. There are studies of formative or exploratory nature. Research designs for these studies must be so flexible that they can permit the researcher to think about many different aspects of a problem or subject matter.

Where the purpose of the study is to describe vividly and accurately the characters or to determine the frequency of occurrence or association, the major thought or concern is accuracy which has to be emphasized. A suitable research design for such a study minimizes bias and maximizes the reliability of collected evidence. Since bias results from subjectivity of facts, reliability can be attained through objectivity and by asserting confidently that repeating the collection facts or evidence would produce similar findings. Descriptive studies satisfy their conditions and reflect appropriate designs.

Experimental researchers permit inferences about causality and test causal hypotheses. View use procedures that only reduce bias but also increases reliability. Experimental researchers are the only ones that are concerned with testing hypotheses about causal relationships. Other studies permit function.

The impression that these different types of study are sharply distinguishable is wrong and should never be entertained.

A research of one type may have in it three or more of the functions described as characterizing different types of study. A primary emphasis, in any single study, is usually on one only of these functions. On 
this basis, the study can be thought of as falling into category corresponding to its major functions. By and large, the distinction among the different types of study is for the purpose of discussing appropriate research design. (Ikeagwu: op Cit: 68)

\subsection{What Is Research Design?}

Different authors have defined and explained research design in their own ways. Research design provides the glue that holds the research is used to structure the research to show how all of the major parts of the research project. The samples or groups, measures, treatment or programs and methods of assignment work together to try address the central research questions (Troachim W.M.K: 2006)

Planning is essential in research and experimental research needs to be planned. Planning in experimental research id the designing of the experiment. This planning in research in general, is research design. Design as it is used in pure research in pure research context refers to the total constructional plan or structure of the research framework. Research design therefore means the structure and planning of the entire approach to a problem for research (Ikeagwu: op Cit: 166).

Design is also used in the statistical sense to refer to property of the analysis necessary to prepare data for interpretation (Leedy 1980:167 in Ikeagwu 166).

An approach from the point of view of content analysis describes research design as a plan for collecting and analyzing data in order to answer the investigator question. A good research design makes explicit and integrates procedures for selecting a sample of data for analysis, content categories and units to be placed in categories, comparison between categories, and the classes of inference which may be drawn from data. It thus implies that the investigator has clearly thought the rationale for the enquiry, that he knows the kind of analysis that he makes once those data are gathered and coded and the inference they permit him to make. In short, a good designing ensures that theory, data gathering analysis and interpretation are integrated (Holsti: 1969:24 in Ikeagwu op Cit: 167).

A view on marketing design asserts that research design is the specification of procedures for collecting and analyzing the data necessary to help identify a problem or to help solve the problem at hand such that the difference between the cost of obtaining various levels of accuracy is maximized

Social relations define research design as the arrangement of condition for collection and analysis of data in a manner that aims to combine relevance to purpose with economy in procedure.

Some aspect of definition needs to be emphasized, first, research design requires specification of procedures. These procedures involve decision on what information to generate, the data collection method, the measurement approach, the object to be measured and the way in which the data are analyzed. Second, data are collected to help to help identify ofr solve a problem. In applied research, all data collection should eventually relate to decisions faced by management. Obviously, collecting data relevant to the problem requires that the problem be clearly defined.

A third implication of the preceding definitions is that the information has value. Information acquires value as it helps to improve decisions. The fourth major implication is that varying the levels of accuracy of information can be generalized in response to the same problem. Information accuracy is affected by the occurrence of number of potentials errors. Finally the goal of applied research design is not to generate the most accurate information possible. Rather the objective is to generate the most valuable information in relation to cost of generating the information (Ikeagwu, op Cit: 167).

Finally, research design means the plans or entire blue print on how to go about data collection and analysis all aimed at providing solutions to the problem under investigation. It entails the specification of procedures that would be deployed in the field work.

There is however, another aspect of research design that merits attention. It refers to the structural frame work which defines the nature of research one is carrying out. The structural makeup of the study could define any of the following designs;

Experimental research design

Historical research design

Survey research design

Case study research design etc.

In most cases, it is expected that one should state the kind of research design one is adopting. This expedient in that it helps to provide the context in which such a study will be appraised.

\subsection{Purpose Of Research Design}

Research designs answer some crucial questions such as;

How was the data collected or generated?

How was it analyzed?

In other words it shows your reader how you obtained your results and why? 


\section{Below Are Some Of The Reasons For Research Design.}

1. We need to know how the data was obtained because the method affects the result. For instance, if you are investigating user's perception of public transportation in Enugu, you will obtain different results if you use a multiple choice questionnaire than if you conduct interviews. Knowing how the data was collected helps the reader evaluate the validity and reliability of your results and conclusion you draw from them.

2. There are different methods. Your methodology should make clears the reasons why you close particular Method or procedure.

3. It reveals the fact that the data was collected or generated in a way that is consistent with accepted practice, in the field of study for example, did your questionnaire give respondent a reasonable range answers to choose from. If for intendance your range of answers provides options such as excellent, very good and good, it can be seen that it is not acceptable since it did not give room for negative answers.

4. Research methods must be appropriate to the objectives of study for instance, if you perform a case study of one commuter in order to investigate user's perception of efficiency of public transport in Enugu, your method is obviously unsuited to your objective.

5. The methodology should also discuss the problem that were anticipated and explain the steps taken to prevent them from occurring and the problem that did occur and the ways their impact was minimized.

6. In some cases, it is useful for other researchers to beast or replicate your methodology. So often, sufficient information is given to allow others to use the work. This is particularly the case when a new method is developed (Zirath A.I.B. (1999).

\section{Definition And Meaning}

A survey can be understand as comprising of district characteristics which relate to the way in which information about the object of study is gathered. The characteristics of this information in a survey involve that.

1. You collect information over a cross section of the population or universe

2. You collect data for a relatively large number of cases in the population.

3. You collect data through the use of structured data gathering devices such as questionnaire or interview schedule

4. You collect data at one point in time

5. You collect data and analyze quantitatively (Unyimadu, op Cit 42)

Surveys represent one of the most common types of quantitative social science research. In survey research, researchers select a sample of respondents from population and administers a standardized questionnaires to them. The questionnaire or survey can be a written document that is completed by the person being surveyed an on line question, a face to face interview or telephone interview. Using survey it is possible to collect data from large or small populations.

Different types of survey are actually composed of several techniques developed by a variety of disciplines. For instance, interviews began as a tool primarily for psychologists and anthropologist while sampling got its stats in the field of agricultural economics. Survey research does not belong to any one field and it can be employee by almost any discipline. It is this capacity for wide application and broad coverage which give the survey technique its greatest usefulness..."(Angus and Katona (1953), in Palmquist mike, 2005) a survey is a form of planned collection of data for the purpose of description as a guide to action or for the purpose of analyzing the relationship between certain variables (Oppenhein, 1970 in Ikeagwu op Cit: 171) in contrast with laboratory experiments which land to be on a smaller scale but more intensive, surveys are usually conducted on a fairly large scale.

Surveys may be undertaken simply to provide someone with information. A government department want to know how much people spend on good, a political aspirant may be curious to have an idea of the number of registered voters in different constituencies that would likely support him. In each case, the survey has a clear descriptive suppose. So also is that of a social scientist who is studying conditions, relationships and behavior. For example, he may be interested in the relations between family size and level of education. Some enquiries aim to explain rather than to describe theoretical or practical functions. They may set out to test some suggested hypotheses or to assess the influence of various factors which can be manipulated by public action upon some phenomenon.

It is essential to consider surveys very well and to subject them to thought and desk research to highlight their limitations and capabilities. Sound judgement in their use depends on these painstaking ground works. To apply blindly the formal standardized methods generally used in official research enquiries to many of the more complex problems in which to attain greater depth by more intensive methods of attack, the deliberate sacrifice of qualitative precision which makes good judgment is required. There are types of field research that do not call for the apparatus of large scale sample survey. 
Surveys are useful both in leading to the formulation of hypotheses and at more advance stage, in putting them to test their function in a given research depends on what is already known about the subject and on the purpose for which the information is required (Ikeagwu, 1998:171).

\subsection{Steps In Executing A Survey Design}

The following steps are undertaken when executing a survey design

1. Research question formulation

2. The determination of the sampling plan

3. Specific choice of what survey technique to be used

4. Designing the data gathering technique

5. Actually carrying out the survey

6. Data analysis (Unyimadu, op Cit: 43).

A survey research is a research and you have to first select the research question. There are well structured question designed to guide the research question. These are well structured question designed to guide the researcher in data collection and whose answers provide solution to the problem under investigation to the problem under investigation. The next is to decide on the plan sampling plan. A sampling plan suggests that a repeated study on samples can give results very close to that obtained from the true population figures. It involves the specification of how each of the decisions on population definition, sampling frame, sampling units sampling method and sample size determination are implemented.

Thirdly you choose the survey technique that is cross sectional design or panel design. In cross sectional design you study a characteristic of the same elements at the same time (that is as short a time period as possible) and this likened to taking the photograph of a street one time. But in panel design you study a characteristic of the same elements at different a time that is you take the photograph at different times. It is a time series design or longitudinal design.

\section{Data Gathering Techniques}

This is the fourth step in executing a survey design. There are essentially three methods:

1. Face to face interview

2. Self-administered questionnaire

3. Telephone interview

\section{The Questionnaire}

Questionnaire is the instrument, commonplace though it may seem, for observing data beyond the physical reach of the observer. The minds, attitudes, feelings and reactions of people conceal data the same way that the sea conceals oil which is beneath it. A took devised to problem below the surface to extract data from the mind, feelings, etc. Is the questionnaire. Two types of questionnaires may be considered at the moment. One is the questionnaire which is generally mailed or given to the subjects to fill in with no help from the researcher. Another is a situation where the instrument is not given directly to the subject. This type is generally called the interview schedule. The subjects among whom the questionnaires are distributed may not be within reach all the time, some may be thousands of miles away and may never be seen by the researcher. In other words, the questionnaire is totally impersonal probe, and as such needs to be governed by several guidelines when it is used as a tool in survey research.

Another aspect of the subject is the questionnaire design which is intimately related to the general plan for design of the survey. A questionnaire is not just a list of questions or a form to be filled out. It is essentially a scientific instrument for measurement and for the collection of particular kind of data. Like all such instruments, it has to be specially designed according to particular specification and with specific aims in mind, and data it yields are subject to error. A questionnaire cannot be judged good or bad, efficient or inefficient unless, the job it was meant to do is known. This means that the design of the investigation as a whole has to be thought of first before the wording of particular questions.

In face to face interview, information is obtained through direct face to face interaction with the respondent. The questions are structured or semi structured. Question can be classified thus enriching your data. It is expensive but the quality of response you get is enhanced. The survey has a lower cost compared to interview. The anonymity of the respondent in an interview gives it an edge over a personal interview, although perhaps not as anonymous as in mailed studying amongst other limitations in the telephone interview is that respondent are less motivated probably because the interview has no real power to continue the interview.

The questionnaire can be mailed or self-administered i.e. distributed by hand. The mailed questionnaire has the advantage of being cheap and the respondent are not under direct pressure and so answers are well considered. The discretion in time means the respondent can eventually lose or throw it away. Questionnaire can 
be structured or unstructured. The structured questionnaire provides all the possible answers from which the respondents are asked to choose. An unstructured questionnaire does not have determined answers. The respondent is asked to provide the answers.

\subsection{Specific Guidelines For Constructing A Questionnaire}

1. Here, you try to motivate the respondent by stating why you are carrying out the survey like saying you are a student and the information will help to improve productivity or help you complete your course. The advantage is that the individual filling it can make an appeal.

2. Order of questions it is necessary to arrange the questions in order in which the data will be analyzed

3. Form of question will the question be structured or unstructured?

4. Clearly the question should not be ambiguous

5. Bias

Do not ask any question to slant the respondent and avoid suggestive question

6. Cross checking question this is important because questions that are properly worded would provide the type of answers you have in mind.

7. Interviewer control self-completion of the interviewer (e.g. student). One way is to write out what the interviewer is to do so you can cross check. You should have a space for stating whom he or she interviewed, where and the name of the respondent and you can go to check.

8. Pre test

It is also necessary to pre-test the questionnaire. Administer it on a percentage of the pimple and see if the responses test the characteristics and see if the instrument is good, otherwise, you redesign the question (Unyimadu, op cit: 45)

For self-administered questionnaire: the problem here is returning the questionnaire.

Ways to overcome this problem include:

1. Add an introductory letter

2. Add stamped addressed envelope

3. Add a financial bonus

4. Make sure your questionnaire is short

5. Send reminder letters if questionnaire are not returned

6. Visit them

In face to face interview the problem here is lack of co-operation ways to overcome this include:

1. Pleasant personality-smile and be friendly

2. If you are not interviewing train your team in the rapport or human resources techniques, answer the respondent sir etc.

3. Go back and leave notes and call back. (Unyimadu, op cit: 46)

\subsection{Definition And Meaning}

\section{Case Study}

Case study can be defined as the background, development, current condition and environmental interaction of one or more individuals, groups, communities, businesses or institutions is observed, recorded and analyzed for stages of patterns in relation to internal and external influences (Zirath, A.I.B, 1999).

According to Becker (1977), a case study comes from a tradition of medical and psychological research when it refers to edited analysis of an individual that explicates the dynamics and pathology of a given disease. The method exposes that one can properly acquire knowledge of a phenomenon from an intensive exploration of a sample case:

The survey method does not tell you how the present depends on the past but the case study does. (Unyimadu, op Cit: 46).

\subsubsection{How To Collect Information In Case Study:}

1) Information is collected for a sample case or a relatively few number of case

2) In gathering information for the sample case or a relatively few number of cases, it uses unstructured method of data collection, for example, intensive interview, observation of the use of secondary materials.

3) It provides information on the subject matter over an extended period of time and it acts as an indicator or process.

4) The basic use of the case study is to generate a theory as opposed for testing theory as against the survey method. Though this is not the case all the time according to Glaser and Strauss (1979), (In Unyimadu, op Cit: 47). 


\subsection{Types Of Case Study}

1) Intensive interview

2) Observation

\subsubsection{Intensive Interviewing (Historical Analysis)}

Intensive interview as a data gathering technique can be seen as a relative probing of a respondent by an interviewer. There are three interacting variables, the respondent, the interviewer, and he interview schedule or questionnaire.

Interview can be structured or standardized, semi structured or non-schedule standardized and unstructured. (Unyimadu, op Cit: 48).

In the structured or standardized, all questions are ask in the same way and the same order of all questions. In semi structured or non-schedule standardized, the same questions are asked but in the end all questions are asked.

In the non-standardized or unstructured, there is no list of questions but you simply that may be relevant depending on how the respondent replies to the earlier questions. There is no interview schedule.

The Problem of Access

This is a big problem in interview, that is, the interviewer having access o he respondent as and when desired. One major advantage of intensive interviewing I that the respondent do it as an occasion quite different from the setting and so they are quite willing to participate.

Goffman (1968), says when you are interviewing people, you are playing the role of an opening, that is, a person who by the nature of his work like the newspaper reporter are granted the license of interviewing people not normally given to others.

\section{How To Prepare For Intensive Interview}

To prepare for an intensive interview, it is important to read up all the existing literature or the research problem and the acquired background knowledge of the organization you are going to.

\section{How To Execute The Intensive Interview}

When you are going into the organization or when you meet a potential respondent, you must first introduce yourself. For organizations you first write a letter to the organization and this serves as introduction. The first interview does not guarantee future association. You introduce the topic. You can take a tape recorder or take notes but not that interpreting a tape is very time consuming.

\section{How To Control The Interview}

You control the interview by guiding the interview or respondent into productive end. Bring him back from digressions. You must also control the pace of the interviewee and interviewer not to take too long.

\section{Non Verbal Indications}

These are behavioral signals given up by the interviewer or the interviewee which may not be necessarily be put in terms of words e.g. laughing. You can record the laughs in a long time in answering a particular question, you can use facial expression in controlling the interview. You can make expression like 'really' or 'is it how it happened'

\section{Rapport}

It is important that occasionally as the respondent talks, you thank him again and again and at the end you thank him and tell him the information is very useful. You can write him a letter of appreciation.

\section{Setting}

The setting in which the interview takes place is very important. If the respondent is too busy, you can change the venue and time.

\section{Advantages}

1) You can collect a lot of information by intensive interviewing as frowning and facial expression and a lot of qualitative data are collected.

2) Interviews are flexible

3) The interview situation can be controlled and standardized through conducting the interview in privacy, ensuring that there is no noise

4) The researcher has the opportunity to compare answers that were given before and after certain events. 


\section{Disadvantages}

1) It is difficult to analyze all the data especially if the data is qualitative

2) Interviews can be extremely costly in terms of time consumed, payments for people employed, and sampling etc.

3) The subject may have no time to conduct research, consult books or other people, check records or ponder his answer.

\subsubsection{Observation}

In observation, we find that researchers can see the world as their subjects also see it, that is, they can capture their subject in their own territories. Unyimadu (2005) quoting Schwartzman Strauss(1973:9) writes that 'the method of observation is based on the method on the assumption that in studying persons where they live and work, social scientists will be in a position to maximize their ability to grasp the motive, values, beliefs, concerns, troubles and interests that underlie the actions of their subjects'.

In observation, you first of all start with a general idea of the problem you want to investigate. Then you choose a research site. In the choice of research site, there is always a problem. It is the choice of the research site that indicates the information you will get and the roles you can play.

roles

1) You can be a complete observer. That is, you get detached of the setting and watch what is happening.

2) The role observer as participant.

In this case you are involved in what is happening but you don't tell them you are investing the group

3) Participant as observer.

You are involved and you also reveal your role as a researcher.

4) You can be a complete participant.

You become fully involved both behaviorally and emotionally.

What role you play within a particular setting depends on how open the membership is. If activities are not secret, you can reveal your role.

Once people know you are a researcher, it will limit the rate of response. (Unyimadu, op cit: 51)

\subsection{Summary}

\section{Summary And Conclusion}

Research design simply means the plan or blue print on how to go about data collection and analysis all aimed at providing solution to the problem under investigation.

For this study, the survey and case study research designs were discussed. For the purpose of refreshing one's memory, a survey consists of asking questions of a (supposedly) representative cross section of the population at a single point in time while case study involves studying individuals, groups etc. in their natural environment. It can be carried out through intensive interviewing and observation.

\subsection{Conclusion}

The importance of research design cannot be over-emphasized. It is here that the researcher stamps his scientific status on the process.

Consequently, it must be done in such a way that any doubting Thomas can repeat the process in an attempt to verify the findings.

For this reason, there is need to exercise care in choosing the appropriate design to suit the type and purpose desired.

\section{Reference}

[1]. Holsti, Ole R. (1996). Content analysis for the social sciences and Humanities (massachussets: Additional wesly publishing company).

[2]. Ikeagwu, E. K. (1998). Groundwork of research: methods and procedures. (Enugu: Institute of development studies University of nigeria, enugu campus.

[3]. Leedy, Paul D. (1980). Practical Research: planning and design (new york: macmillan publishing company, inc.)

[4]. Oppenhein, A. N. (1970). Questionnaire design and Attitude measurement (london: Heinemann educational books ltd.)

[5]. palmquist, mike(2005). Survey Research. Colorado state university, department of english. (Http//writing.colostate.edu/guides/research/survey/).

[6]. Sellitz, claire et al (1959). Research methods in social relations (new york: Holt, Rineharrt and winston publishing).

[7]. Troachim, W. M. K. (1998). Center for Design research. (http://www.socialresearchmethods.net//kb/design.php).

[8]. Unyimadu, S. O. (2005). Research methodsand procedures. (benin city:The guide press)

[9]. Zirath angelov, i. B. (1999). Writing up Research: method and research design. (http://www.languages.ait.ac.th/el21 meth.htm) 